\title{
DESEMPENHO TÉRMICO DE ARGAMASSAS COM AGREGADO DE RESÍDUOS INDUSTRIAIS - ESTUDO DE CASO DE UMA EDIFICAÇÃO DE ALTO PADRÃO
}

\author{
MENDES, JÚLIA \\ Engenheira Civil, D.Sc \\ Universidade Federal de Ouro Preto \\ Minas Gerais; Brasil \\ julia.mendes@ufop.edu.br \\ NOGUEIRA, MARCELA \\ Mestranda em Engenharia Civil \\ Universidade Federal de Ouro Preto \\ Minas Gerais; Brasil \\ marcela.nogueira@aluno.ufop.edu.br \\ VILAÇA, VANESSA \\ Arquiteta e Urbanista \\ Universidade Federal de Ouro Preto \\ Minas Gerais; Brasil \\ vanessatognini@hotmail.com
}

\author{
ELÓI, FERNANDA \\ Mestranda em Engenharia Civil \\ Universidade Federal de Ouro Preto \\ Minas Gerais; Brasil \\ fernandaeloi94@gmail.com \\ SOUSA, HENOR \\ Engenheiro Mecânico, D.Sc \\ Universidade Federal de Ouro Preto \\ Minas Gerais; Brasil \\ henor@ufop.edu.br \\ PEIXOTO, RICARDO \\ Engenheiro Civil, D.Sc \\ Universidade Federal de Ouro Preto \\ Minas Gerais; Brasil \\ fiorotti.ricardo@gmail.com
}

\section{RESUMO}

Sabe-se que a demanda por edificações cada vez eficientes energeticamente tem crescido a nível mundial e que o sistema de vedação dos edifícios tem grande influência no conforto ambiental e, consequentemente, na vida de seus usuários. Nesse contexto, o presente trabalho avalia o desempenho térmico de argamassas de revestimento produzidas com resíduos industriais e de mineração através de uma simulação em uma edificação existente de alto padrão. Foram feitos ensaios para avaliar a condutividade térmica e massa específica de argamassas compostas com quatro tipos de agregados: areia de rio (REF), rejeitos de minério de ferro (RBMF), quartzito friável (QZTO) e escória de aciaria (ESC). Em seguida, foi feita uma análise de desempenho térmico da edificação para avaliar a temperatura interna a partir dos aspectos naturais de temperatura e ventilação que incidem na residência. Devido à baixa condutividade térmica e à alta massa específica, a argamassa com ESC obteve os melhores resultados de desempenho térmico, seguida por aquelas com RBMF, REF e QZTO. No cenário atual em que os agregados naturais estão se tornando cada vez mais escassos, essa avaliação abre caminho para materiais de construção mais sustentáveis, com baixo consumo energético, maior desempenho e durabilidade, prevenindo assim, futuras patologias e consequentemente diminuindo a demanda de manutenção.

Palavras-chave: reutilização de resíduo, condutividade térmica, simulação energética, desempenho das edificações.

\begin{abstract}
Demand for increasing the energy-efficient buildings is known to have grown worldwide and the building envelope system has a major influence on the therml comfort and, consequently, on the lives of its users. In this context, the present work evaluates the thermal performance of coating mortars produced with industrial and mining residues through an energy simulation of an existing high standard building. Tests were performed to evaluate the thermal conductivity and specific gravity of mortars composed of four types of aggregates: river sand (REF), iron ore tailings (RBMF), friable quartzite (QZTO) and steel slag (ESC). Then, a thermal performance analysis of the building was made to evaluate the internal temperature from the natural aspects of temperature and ventilation that affect the house. Due to the low thermal conductivity and the high density, the mortar with ESC obtained the best performance, followed by those with RBMF, REF and QZTO. In the current scenario where natural aggregates are becoming increasingly scarce, this evaluation open space for more $\mathrm{r}$ more sustainable building materials with lower energy consumption, higher performance and durability, thus preventing future pathologies and consequently requiring lower maintenance demand.

Keywords: reuse of residues, thermal conductivity, energy simulation, performance of buildings.
\end{abstract}




\section{INTRODUÇÃO}

Sabe-se que a vedação de um edifício é um dos sistemas mais críticos que afetam a eficiência energética de uma edificação (SADINENI, MADALA e BOEHM, 2011). Várias tecnologias promissoras vêm sendo desenvolvidas no âmbito dos sistemas de vedações das construções, mais ainda há uma resistência a esse tipo de tecnologia pelo aumento do custo da obra em projetos com eficiência energética. Nesse sentido, materiais de construção com alto calor específico e baixa condutividade térmica promovem uma diminuição nas taxas de transferência de calor durante o horário de pico e reduzem as flutuações da temperatura interior das edificações (SONG, NIU, et al., 2018).

Ao mesmo tempo em que se torna cada vez mais importante a eficiência energética, os recursos naturais utilizados na produção de materiais na construção civil geram um grande impacto ambiental. Devido à urbanização e ao aumento da população, a demanda por recursos naturais aumenta em todo o mundo. Bilhões de toneladas de rejeitos de mineração e resíduos industriais são assim gerados e descartados todos os anos, com altos custos ambientais e sociais (EDRAKI, BAUMGARTL, et al., 2014).

Nesse cenário, o uso de resíduos como materiais de construção implica não apenas em uma redução significativa na energia incorporada de um edifício, mas também mitiga o consumo de recursos naturais. Além disso, essa prática tem o potencial de reduzir os custos de construção e, muitas vezes, melhorar as propriedades técnicas das matrizes cimentícias.

Como exemplo, rejeitos de minério de ferro obtidos de barragens de rejeitos foram estudados por Sant'Ana Filho, et al. (2017) e Fontes, et al. (2016) com sucesso como agregado. A escória de aciaria processada também foi amplamente estudada como agregado para construção civil por Carvalho et al. (2019) e Silva et al. (2016) , entre outros. Outro resíduo promissor é o quartzito friável, obtido a partir da produção de rochas ornamentais. Santos (2015) e Dias (2017) utilizaram com sucesso a fração fina para argamassas de revestimento e adesivas.

Atualmente, com a intensificação do detalhamento do projeto, o amplo uso de softwares de simulação e o desenvolvimento de novos materiais, as propriedades térmicas dos materiais de construção são cada vez mais exigidas. Em geral, as características físicas e mecânicas de pastas, argamassas e concretos são encontradas na literatura com relativa facilidade, diferentemente de suas propriedades térmicas e também a substituição total de agregados naturais por mineração e/ou resíduos industriais. Além das propriedades térmicas, um bom desempenho de argamassas previne futuras patologias das edificações, como fissuras, infiltração e ataque de agentes agressivos.

Esse tipo de abordagem traz além de soluções economicamente vantajosas, novos materiais empregados na construção civil que podem proporcionar soluções energética com baixa demanda de manutenção. E para além das questões ambientais, econômicas, técnicas e normativas, o melhor desempenho térmico promovido pelos rejeitos também pode aumentar a saúde, a produtividade e a felicidade, reduzindo assim a privação social sofrida por famílias de baixa renda em ambientes termicamente estressantes (PATINOA e SIEGEL, 2018).

Nesse contexto, o presente trabalho avalia o desempenho térmico de argamassas de revestimento produzidas com resíduos industriais e de mineração. Para isso, investigou-se o efeito de quatro tipos de agregados (areia de rio, rejeitos de minério de ferro, quartzito friável e escória siderúrgica) nas propriedades térmicas de uma argamassa de revestimento. Procurando entender como essas propriedades influenciam o desempenho térmico de um edifício em diferentes climas, uma edificação residencial existente foi simulada em oito zonas bioclimáticas. No cenário atual em que os agregados naturais estão se tornando cada vez mais escassos, essa avaliação abre caminho para materiais de construção mais sustentáveis e com baixo consumo energético e maior eficiência.

\section{MATERIAIS E MÉTODOS}

O presente trabalho avalia o desempenho térmico de argamassas de revestimento com resíduos industriais e de mineração através de uma simulação energética em uma edificação de alto padrão existente. Foi produzido um tipo comum de argamassa de revestimento (reboco), com cimento Portland de alta resistência inicial (CPV-ARI), cal hidratada, agregados miúdo e água potável com proporções de mistura de 1:1:6 (cimento: cal: agregado fino), em volume. O traço de referência (REFm) representa as argamassas produzidas com areia natural de rio como agregado. Nas outras argamassas foi feita a substituição total dos agregados miúdo por lama de barragem de minério de ferro (RBMFm), quartzito friável (QZTOm) ou escória de aciaria (ESCm). As amostras dos resíduos foram coletadas representativamente, de acordo com as prescrições normativas da NBR 10007 (2004). 
A RBMF utilizada no presente trabalho é proveniente de uma barragem de rejeitos localizada na cidade de Igarapé, estado de Minas Gerais. O QZTO é proveniente da cidade de São Thomé das Letras, Minas Gerais. Por sua vez, a ESC, resíduo do processo de produção de aço de Linz-Donawitz (LD), é originária da cidade de João Monlevade, Minas Gerais.

Antes da mistura, tanto os agregados naturais quanto os de resíduo foram peneirados, sendo adotadas as frações passantes na malha $\mathrm{n}^{\circ} 4(4,75 \mathrm{~mm})$. Os agregados foram posteriormente secos em estufa a $105^{\circ} \mathrm{C}$. Após secagem, as argilas aglomeradas e as partículas friáveis da RBMF foram destorroadas manualmente. O QZTO, por sua vez, foi utilizado no estado bruto.

Para preparação da ESC para utilização como agregado, ela foi submetida a irrigação por um período de um ano, a fim de hidratar completamente seus óxidos livres $(\mathrm{CaO}$ e $\mathrm{MgO})$ que poderiam gerar problemas de expansibilidade na matriz. Posteriormente, o material foi submetido a trituração em um moinho de mandíbulas, para reduzir o tamanho das partículas às de agregados finos $(<4,75 \mathrm{~mm})$.

Em sequência submetido a processo de separação magnética, na qual a fração metálica retornou ao ciclo de produção de aço, enquanto a fração não metálica originou os agregados utilizados neste trabalho. Os agregados foram dividos em frações granulométricas a fim de obter a mesma distribuição de tamanho de partículas da areia natural de rio.

\subsection{Caracterização do materiais}

A distribuição granulométrica de todos os agregados foi obtida por difração a laser(para as frações $<0,075 \mathrm{~mm}$ ), com equipamento BETTERSIZE 2000 (Figura 1). Como já citado anteriormente, os agregados de escória de aciaria (SLG) foram produzidos para ter a mesma distribuição granulométrica do agregado convencional. A partir desse ensaio, foi possível observar que $50 \%$ das partículas de RBMF são menores que $0,05 \mathrm{~mm}$, mostrando que esse material é particularmente fino e bem graduado. Já o quartzito (QTZO) apresentou 50\% de suas partículas menores que 0,2 mm, seguida pelos agregados de areia de rio e SLG com 50\% das partículas menores que 0,5 mm.

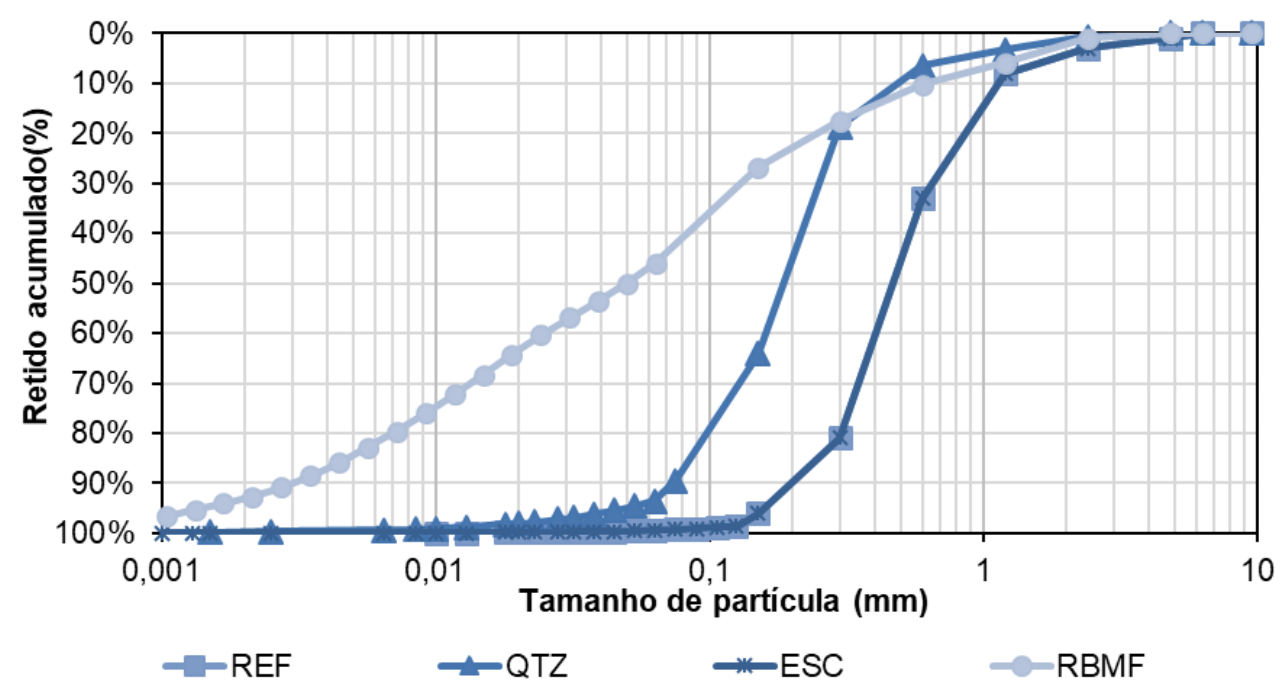

Figura 1 - Distribuição granulométrica dos agregados

A caracterização mineralógica foi determinada pela difração de raio X (DRX) pelo equipamento Bruker D2 Phaser, operado com configuração de medição Bragg - Brentano, radiação $\mathrm{CuK} \alpha 1,2(\lambda=1,5408 \AA$ ) $), 45 \mathrm{kV}, 40 \mathrm{~mA}$; velocidade de rotação $8 \mathrm{rpm}$; faixa angular $6^{\circ}-80^{\circ} 2 \theta$; tamanho do passo $0,02^{\circ} 2 \theta$; tempo por passo $1 \mathrm{~s}$. A análise dos resultados mostrados na Tabela 1 e o refinamento foi realizado usando o método Rietveld em um software Topas 5.0, auxiliado pelo Crystallography Open Database (COD) 2013. Griceita (LiF), foi usada como padrão interno, adicionada na proporção de $10 \%$ ao valor da amostra massa.

Tabela 1 - Difração de raio $\mathrm{X}$ dos agregados

\begin{tabular}{|c|c|c|c|c|}
\hline Mineral & Areia de rio & QTZO & RBMF & SLG \\
\hline Quartzo & $78.04 \%$ & $89.60 \%$ & $26.32 \%$ & $0.79 \%$ \\
\hline Caolinita & $3.53 \%$ & $4.40 \%$ & $17.53 \%$ & \\
\hline
\end{tabular}




\begin{tabular}{|c|c|c|c|c|}
\hline Mineral & Areia de rio & QTZO & RBMF & SLG \\
\hline Gipsita & $1.95 \%$ & & $5.20 \%$ & \\
\hline Ortoclásio & $5.62 \%$ & & & \\
\hline Flogopita & $2.87 \%$ & & & \\
\hline Muscovita & & $2.85 \%$ & & \\
\hline Hematita & & & $43.62 \%$ & \\
\hline Goethita & & & $2.07 \%$ & \\
\hline Calcita & & & & $12.02 \%$ \\
\hline Wuestita & & & & $11.03 \%$ \\
\hline Brownmielita & & & & $9.31 \%$ \\
\hline Larnita & & & & $8.46 \%$ \\
\hline Outros & & & & $5.74 \%$ \\
\hline Teor de amorfo & $7.83 \%$ & $3.12 \%$ & $5.25 \%$ & $52.65 \%$ \\
\hline
\end{tabular}

A composição encontrada na análise química dos materiais no presente trabalho corrobora com as encontradas na literatura. Assim, observou-se que a areia de rio é composta principalmente por óxidos de silício e alumínio, enquanto o QZTO é composto predominantemente por óxido de silício, que também foi encontrado em teor significativo na RBMF. Entretanto, o teor de minerais à base de ferro, observado na Tabela 1, foi significativamente mais alto no RBMF. A ESC apresentou altos teores de silício, ferro e cálcio. Já na análise mineralógica, foi possível observar que RBMF e QTZO apresentam alto grau de cristalinidade, ao contrário da SLG, que obteve mais de $52 \%$ de teor de amorfos.

Ainda sobre a composição química e mineralógica dos três resíduos estudados no presente trabalho, Bastos et al. (2016), Da Silva et al. (2016) e Santos (2015) a partir de análises ambientais de lixiviação e dissolução, avaliaram respectivamente o nível de contaminação de elementos tóxicos para a ESC, o RBMF e friável QTZO. Os três resíduos foram classificados como classe II segundo a NBR 10004 (2004), portanto, não inertes e não perigosos, portanto, eles não apresentam características perigosas como corrosividade, reatividade, toxicidade, patogenicidade ou inflamabilidade.

Finalmente, a massa unitária e a massa específica aparente dos agregados são mostrados na Tabela 2. Observa-se que a RBMF e a ESC apresentaram maiores massas específicas aparentes, uma consequência de suas composições químicas, ricas em óxidos de ferro. A areia do rio e o QZTO apresentaram densidades muito semelhantes.

Tabela 2 - Massa unitária e massa específicas dos agregados

\begin{tabular}{|l|c|c|c|c|}
\hline & Areia de rio & RMBF & QZTO & ESC \\
\hline Massa unitária $\left(\mathrm{g} / \mathrm{cm}^{3}\right)$ & 2.65 & 3.53 & 2.63 & 3.49 \\
\hline Massa específica aparente $\left(\mathrm{g} / \mathrm{cm}^{3}\right)$ & 1.58 & 1.62 & 1.51 & 1.74 \\
\hline
\end{tabular}

\subsection{Preparação e método de mistura}

A demanda de água foi definida como a necessária para as argamassas atingir espalhamento de $260 \pm 5 \mathrm{~mm}$. A Figura 2 apresenta os resultados para as proporções água/cimento (a/c) e água/ligantes $(\mathrm{a} / \mathrm{l})$; o último considerando cimento e cal juntos como aglomerantes. 


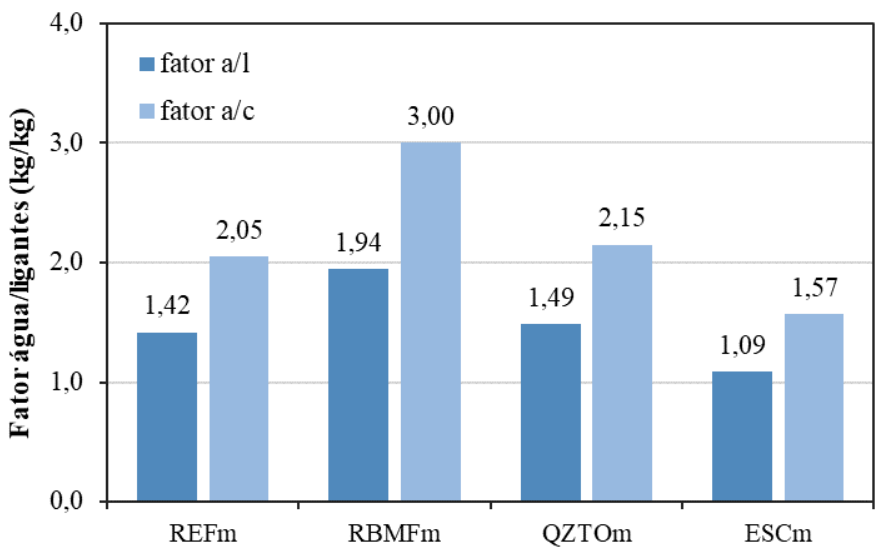

Figura 2 - Fator a/c e a/l das argamassas

As argamassas foram produzidas em um misturador de argamassa convencional, segundo a NBR 13276 (2002). O procedimento de mistura incluiu 1 minuto em baixa velocidade, seguido de $30 \mathrm{~s}$ em alta velocidade. Para cada tipo de agregado foram moldados 4 corpos de prova em forma de placa de dimensões $300 \times 300 \times 50 \mathrm{~mm}$ (para testes de massa específica e condutividade térmica) e 5 amostras cilíndricas de dimensões $5 \times 10 \mathrm{~cm}$ (para testes de índice de vazios). A cura foi realizada em câmara úmida por 28 dias, temperatura $25 \pm 2{ }^{\circ} \mathrm{C}$ e umidade relativa de $90 \% \pm 5 \%$.

\subsection{Caracterização física e térmica}

No estado endurecido, o volume foi obtido medindo as amostras com uma régua em uma escala de precisão. O volume final foi dado pela média de oito medições nos quatro lados das placas. O teste do índice de vazios foi realizado de acordo com a NBR 9778 (2009) nas amostras cilíndricas.

Para a análise das propriedades térmicas, foi utilizado um medidor de fluxo de calor NETZSCH HFM 436 Lambda para obter a condutividade térmica das amostras. Foi adotada temperatura média de $20{ }^{\circ} \mathrm{C}$, com diferença de temperatura de $10{ }^{\circ} \mathrm{C}$ entre as placas frias e quentes. O processo de preparação das amostras procurou reduzir ao máximo a água livre de todas as placas para garantir parâmetros de simulação semelhantes, para isso, as amostras foram gradualmente secas em estufa a $80{ }^{\circ} \mathrm{C}$ até constância de massa. Esse ensaio não possui norma específica nacional ou internacional, portanto, foram seguidas as instruções do fabricante para preparação das amostras.

\subsection{Avaliação do desempenho térmico através da simulação de energia do edifício}

As propriedades físicas e térmicas resultantes foram usadas como dados de entrada para a simulação térmica de uma residência de alto padrão existente (Figura 3). No presente trabalho foi avaliada uma edificação de alto padrão construída com unidades de alvenaria de cerâmica oca, montadas com juntas de argamassa verticais e horizontais (espessura de $1 \mathrm{~cm}$ ). As paredes são cobertas de cada lado com argamassa de revestimento (espessura de 2,5cm; traço 1:1:6). 


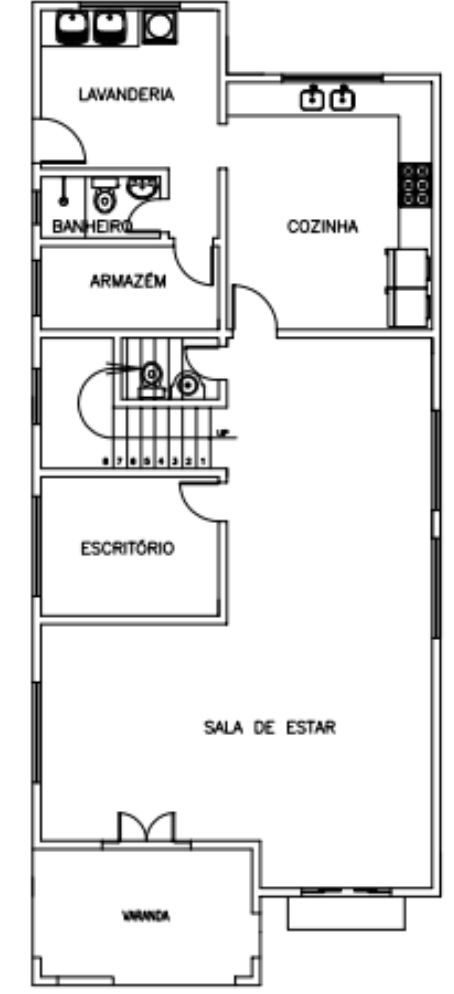

PLANTA DO PRIMEIRO PAVIMENTO

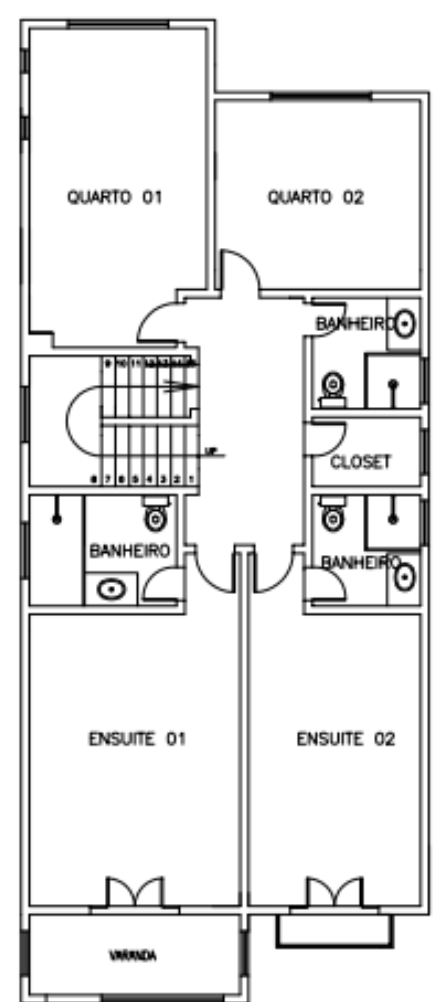

PLANTA DO SEGUNDO PAVIMENTO

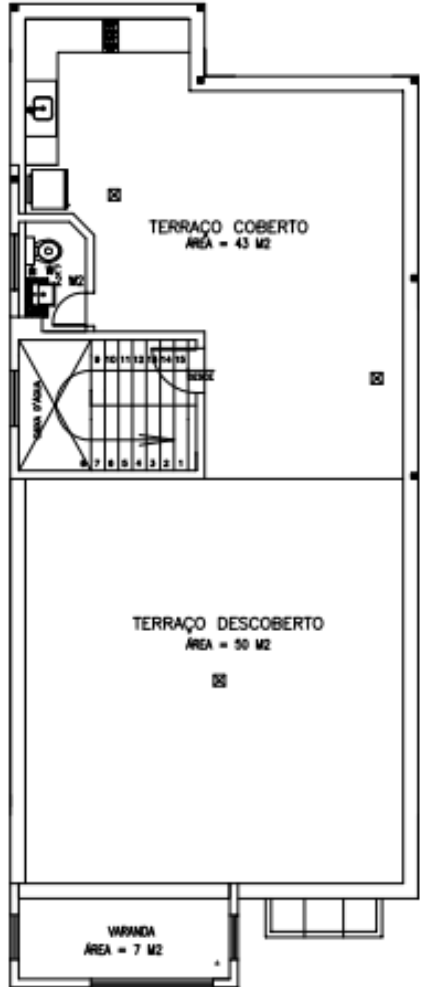

PLANTA DO TERRAÇO

Figura 3 - Planta baixa da edificação avaliada na simulação

A norma de desempenho térmico das edificações, NBR 15220 (2005), apresenta um zoneamento bioclimático do território brasileiro, dividido em oito zonas. Cada zona possui uma recomendação de condicionamento térmico aceitáveis para indicativo de um bom desempenho. As recomendações de cada zona podem ser observadas para o dia típico de verão, na Tabela 3, e para o dia típico de inverno, na Tabela 4. As tabelas não consideram a presença de fontes internas de calor (ocupantes, lâmpadas, equipamentos em geral), buscando isolar os efeitos da vedação do edifício e avaliar o desempenho dos diferentes materiais utilizados no presente trabalho. Foram avaliadas as temperaturas na sala e no quarto mais desfavorável e testadas duas taxas renovação de ar, uma de 1 ren/h e 5 ren/h, de acordo com a norma NBR15220 (2005).

Tabela 3 - Critérios de avaliação de desempenho térmico para as condições de verão

\begin{tabular}{|c|c|c|}
\hline \multirow{2}{*}{ Nível de desempenho } & \multicolumn{2}{|c|}{ Critério } \\
\hline & Zona 1 a 7 & Zona 8 \\
\hline Mínimo & $\mathrm{T}_{\mathrm{i}, \max } \leq \mathrm{T}_{\mathrm{e}, \max }$ & $\mathrm{T}_{\mathrm{i}, \max } \leq \mathrm{T}_{\mathrm{e}, \max }$ \\
\hline Intermediário & $\mathrm{T}_{\mathrm{i}, \max } \leq\left(\mathrm{T}_{\mathrm{e}, \max }-2^{\circ} \mathrm{C}\right)$ & $\mathrm{T}_{\mathrm{i}, \text { max }} \leq\left(\mathrm{T}_{\mathrm{e}, \max }-1^{\circ} \mathrm{C}\right)$ \\
\hline Superior & $\mathrm{T}_{\mathrm{i}, \max } \leq\left(\mathrm{T}_{\mathrm{e}, \max }-4^{\circ} \mathrm{C}\right)$ & $\begin{array}{c}\mathrm{T}_{\mathrm{i}, \max } \leq\left(\mathrm{T}_{\mathrm{e}, \max }-2^{\circ} \mathrm{C}\right) \text { e } \mathrm{T}_{\mathrm{i}, \mathrm{min}} \leq\left(\mathrm{T}_{\mathrm{e}, \min }\right. \\
\left.1{ }^{\circ} \mathrm{C}\right)\end{array}$ \\
\hline \multicolumn{3}{|c|}{$\begin{array}{l}\mathrm{T}_{\mathrm{i}, \max } \text { é o valor máximo diário da temperatura do ar no interior da edificação, em graus Celsius; } \mathrm{T}_{\mathrm{e}, \max } \text { é o } \\
\text { valor máximo diário da temperatura do ar exterior à edificação, em graus Celsius; } \\
\mathrm{T}_{\mathrm{i}, \text { min }} \text { é o valor mínimo diário da temperatura do ar no interior da edificação, em graus Celsius; } \\
\mathrm{T}_{\mathrm{e}, \text { min é o valor mínimo diário da temperatura do ar exterior à edificação, em graus Celsius; }} \\
\text { NOTA Zona bioclimáticas de acordo com a ABNT NBR 15220-3 }\end{array}$} \\
\hline
\end{tabular}

Tabela 4 - Critérios de avaliação de desempenho térmico para as condições de inverno

\begin{tabular}{|c|c|c|}
\hline \multirow{2}{*}{ Nível de desempenho } & \multicolumn{2}{|c|}{ Critério } \\
\hline & Zona 1 a 5 & Zona 6,7 e 8 \\
\hline Mínimo & $\mathrm{T}_{\mathrm{i}, \min } \geq\left(\mathrm{T}_{\mathrm{e}, \min }+3^{\circ} \mathrm{C}\right)$ & \multirow{3}{*}{$\begin{array}{c}\text { Nestas zonas, este critério não } \\
\text { precisa ser verificado }\end{array}$} \\
\hline Intermediário & $\mathrm{T}_{\mathrm{i}, \min } \geq\left(\mathrm{T}_{\mathrm{e}, \min }+5^{\circ} \mathrm{C}\right)$ & \\
\hline Superior & $\mathrm{T}_{\mathrm{i}, \min } \geq\left(\mathrm{T}_{\mathrm{e}, \min }+7^{\circ} \mathrm{C}\right)$ & \\
\hline
\end{tabular}


$\mathrm{T}_{\mathrm{i}, \mathrm{min}}$ é o valor mínimo diário da temperatura do ar no interior da edificação, em graus Celsius;

$\mathrm{T}_{\mathrm{e}, \min }$ é o valor mínimo diário da temperatura do ar exterior à edificação, em graus Celsius;

NOTA Zona bioclimáticas de acordo com a ABNT NBR 15220-3

A simulação do edifício selecionado foi desenvolvida no software Energy Plus (versão 8.6.0) e considerou as seguintes hipóteses:

- Orientação norte;

- Valores de condutividade térmica e massa específica aparente experimentais para as argamassas testadas;

- Paredes compostas por tijolos vazados de cerâmica com $15 \mathrm{~cm}$ de espessura, revestidas com as argamassas investigadas (2,5 cm de cada lado);

- Telhas cerâmicas.

- Para os demais materiais, como cerâmica, concreto, madeira e vidro, foram utilizados os valores de propriedades térmicas e físicas indicados pela NBR 15220;

- Calor específico padrão de $1000 \mathrm{~J} / \mathrm{kgK}$ foi adotado para todas as argamassas, seguindo a NBR 15220;

- Nenhum equipamento de condicionamento artificial foi considerado.

- As condições de sombreamento foram apenas as promovidas pelos beirais do telhado.

- Nenhuma vegetação circundante foi considerada;

- A temperatura do solo adotada foi o padrão do software de $18^{\circ} \mathrm{C}$; não foi considerado material de isolamento;

- As janelas foram modeladas abertas e apenas a ventilação/infiltração natural foi considerada.

- A simulação compreendeu períodos de 3 dias típicos de projeto seguidos (para verão e inverno), conforme indicado pela norma de desempenho térmico NBR 15575 (ABNT, 2013);

- A variação na condutividade térmica dos materiais na presença de umidade não foi considerada.

\section{RESULTADOS E DISCUSSÃO}

\subsection{Caracterização física e térmica}

Os resultados de massa específica e o índice de vazios das argamassas no estado endurecido são apresentados na Figura 4, onde é possível observar que as argamassas com agregados naturais (REFm) apresentaram valores considerados normais, de $1831 \mathrm{~kg} / \mathrm{m}^{3}$.

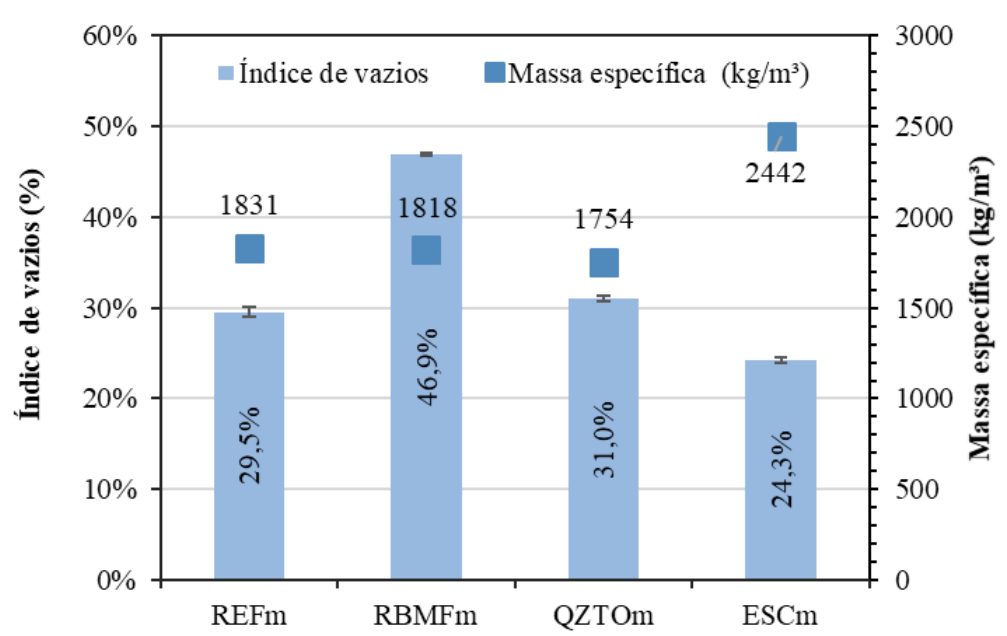

Figura 4 - Índice de vazios e massa específica das argamassas

Apesar do RBMF ter apresentado uma massa específica muito mair do que a areia natural, as argamassas com esse material apresentaram uma massa específica um pouco menor que as REFm, o que pode ser resultado do ar incorporado durante a mistura e o maior teor de água/ligantes dessa argamassa. As QZTOm apresentaram porosidade e massa específica semelhantes às REFm, o que era previsto devido às características físicas e químicas semelhantes de ambos os 
agregados. As ESCm apresentaram a maior massa específica e o menor índice de vazios, provavelmente por causa de suas propriedades químicas e aglomerantes (COSTA, 2019), bem como ao menor teor de água/ligante dessa argamassa.

A Figura 5 apresenta os resultados da condutividade térmica, na qual a estrutura de poros formada pelos agregados foi responsável pela reduzida condutividade térmica de RBMFm e QZTOm. O alto teor de amorfos encontrado na análise mineralógica da ESC contribuiu significativamente para a baixa condutividade térmica do ESCm, já que a baixa rigidez entre as ligações moleculares, materiais amorfos são tipicamente maus condutores térmicos. Esses resultados podem ser observados na Figura 3, apesar de seu índice de vazios relativamente baixo.

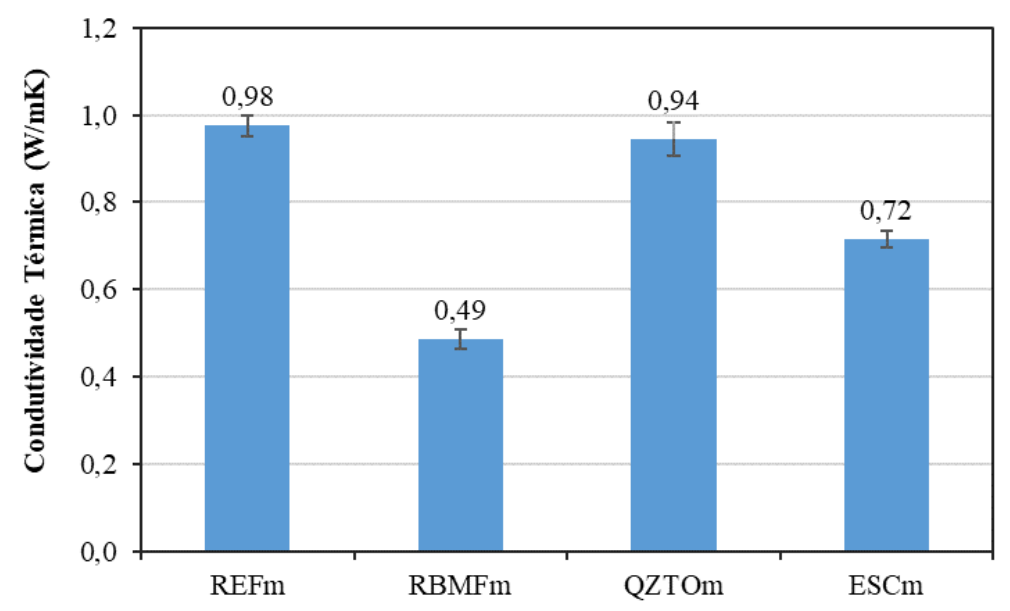

Figura 5- Condutividade térmica das argamassas

Conclui-se então, que um sistema de poros refinado foi gerado em todos os materiais estudados devido ao efeito de preenchimento (QZTO e RBMF), retenção de água (RBMF) e propriedades cimentantes (ESC), que gerou um maior número de poros menores. Esses efeitos, juntamente com o sistema de poros, foram investigados com maior profundidade no artigo de Mendes et. al (2019). A porosidade aumentada reduz a condutividade térmica da fase sólida, já que a condução térmica do ar é relativamente baixa $(0,025 \mathrm{~W} /(\mathrm{mK}))$. Em relação ao maior número de poros menores, eles aumentaram o número de interfaces entre a fase sólida e os poros na matriz, levando a uma condutividade térmica reduzida dessas argamassas (mais expressivamente para RBMFm e ESCm).

\subsection{Avaliação do desempenho térmico através da simulação de energia do edifício}

As Figuras 6 a 7 exemplificam os resultados típicos das simulações. Foram mostrados um dia típico de inverno e um de verão; para Zona 2 e Zona 7, reconhecidas por invernos e verões rigorosos no Brasil, respectivamente.

Zona 2,1 ren/h, Sala- Inverno
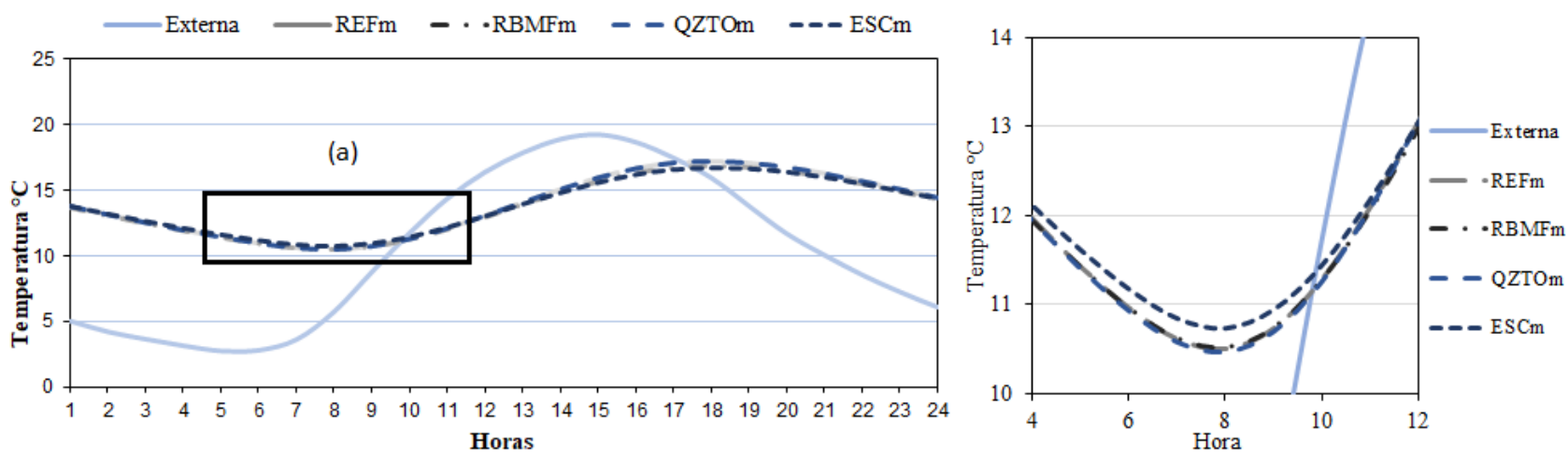

Figura 6 - Simulação para a sala de estar na Zona 2 com 1 ren/h 

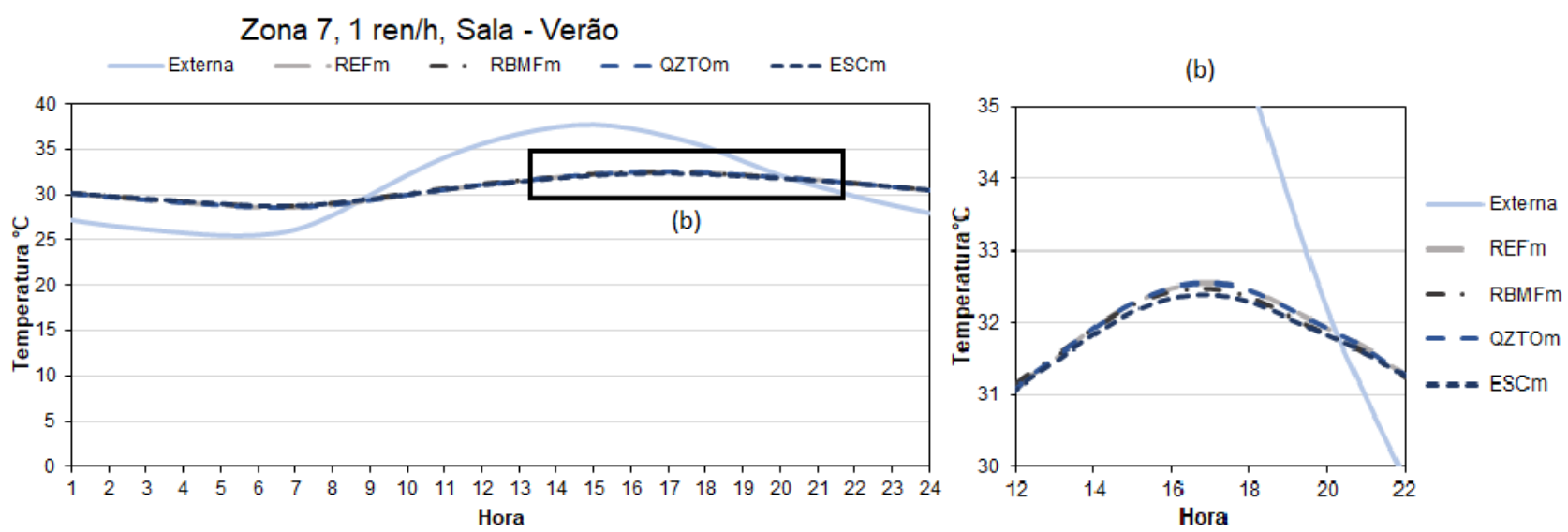

Figura 7 - Simulação para a sala de estar na Zona 7 com 1 ren/h

As simulações mostram um comportamento semelhante para todas as argamassas testadas - um atraso no pico da temperatura interna quando comparado ao exterior e uma redução significativa na intensidade desse pico. As argamassas ESCm e RBMFm apresentaram uma diferença maior na temperatura externa do que as argamassas REFm e QZTOm, com perfis de temperatura comparáveis. Esses resultados sugerem um desempenho aprimorado de isolamento para argamassas ESCm e RBMFm devido à maior massa específica desses materiais.

A Figura 8 resume os resultados dos níveis de desempenho térmico para cada tipo de argamassa, incluindo todas as condições de ventilação e zonas climáticas. Inicialmente, observa-se que as argamassas com escória de aciaria (ESCm) apresentaram o melhor desempenho geral, com a maioria das classificações "superiores" e "intermediárias" e nenhuma "desempenho insuficiente".

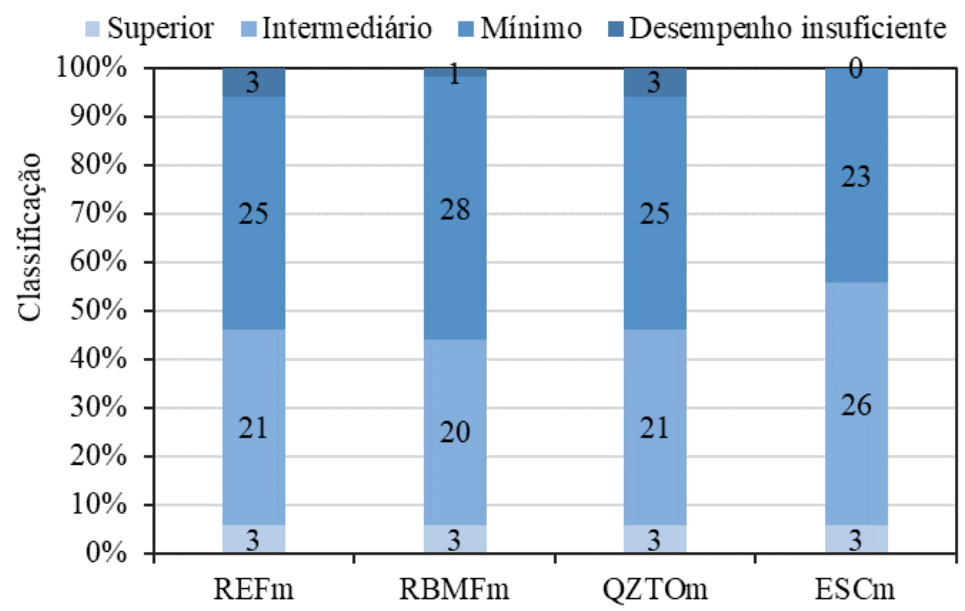

Figura 8 - Classificação quanto ao conforto ambiental de todas as simulações realizadas.

Este desempenho é resultado da baixa condutividade térmica desta argamassa (28\% menor que a REFm), juntamente com a sua alta massa específica (33\% maior). Essa configuração permitiu um alto atraso térmico e, portanto, melhorou a temperatura no ambiente externo. A ESCm foi seguida por RBMFm (apenas 1 desempenho insuficiente) e depois por REFm (3 desempenho insuficiente). As argamassas RBMFm têm uma condutividade térmica significativamente baixa (50\% da REFm) e uma massa específica apenas $1 \%$ menor que REFm. Essa configuração garantiu menos ocorrências de desempenho insuficiente e um número maior de simulações com resultados "superiores" e "intermediários".

Entre as argamassas experimentais, o QZTOm apresentou os piores resultados ( 3 não confortáveis e 54 simulações com níveis "superior" e "intermediário"). Uma condutividade térmica ligeiramente mais baixa ( $4 \%$ menor que REFm) não foi suficiente para contrabalançar a menor massa específica (também $4 \%$ menor que REFm). Esses resultados (juntamente com os do RBMFm e ESCm) indicam que as densidades das argamassas são mais influentes na simulação do que suas condutividades térmicas, quando mantido fixo o calor específico das argamassas. 
A Figura 9 auxilia na comparação entre as diferentes zonas climáticas. Esses números apresentam a diferença de temperatura entre os ambientes internos e externos de cada edifício. A sala com $1 \mathrm{ren} / \mathrm{h}$ foi escolhida para essa avaliação em profundidade, pois apresentava as maiores amplitudes térmicas.

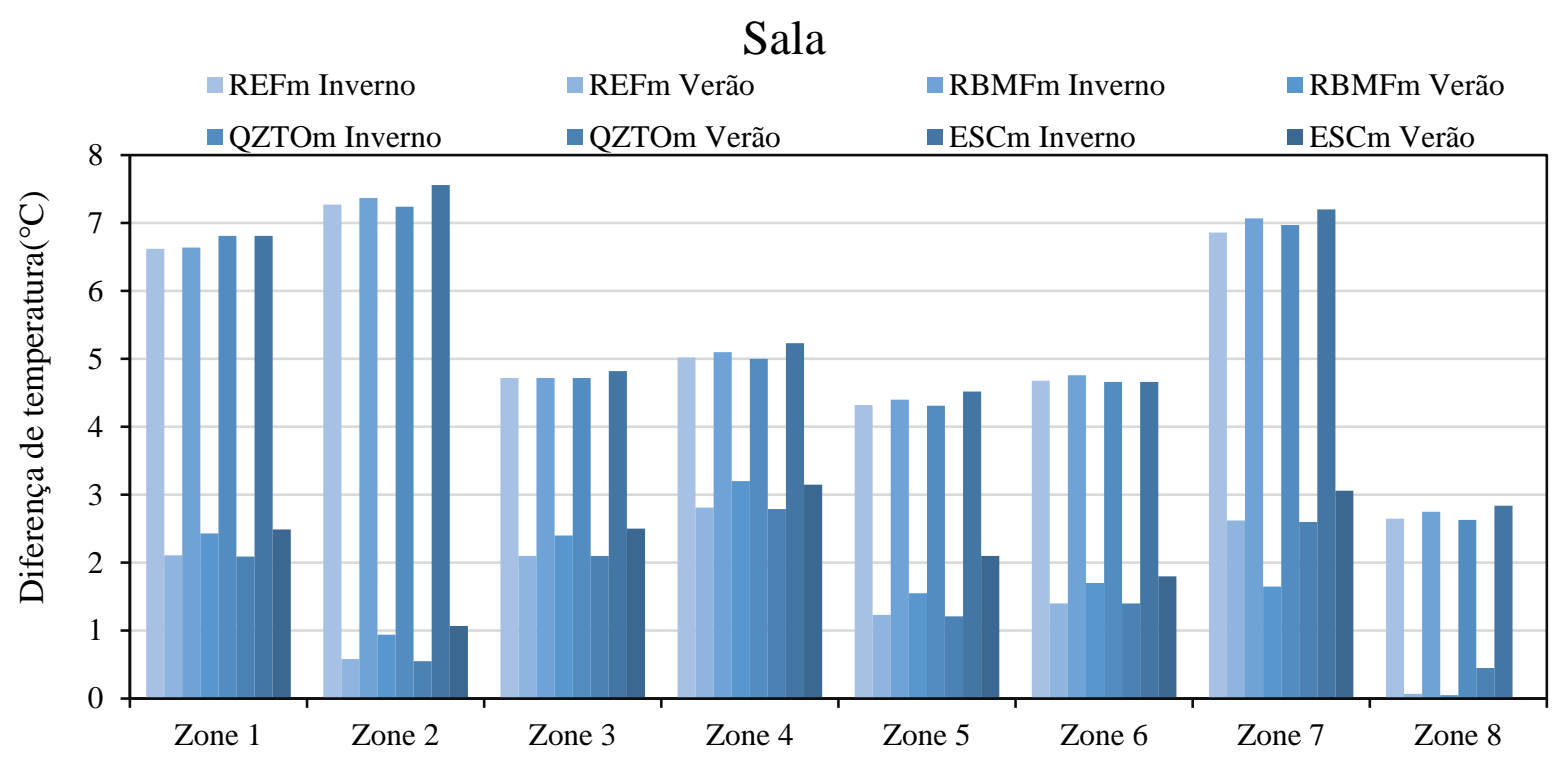

Figura 8 - comparação entre os resultados das diferentes zonas climáticas para 1 ren/h

Os gráficos mostram que as maiores diferenças de temperatura (daí o maior desempenho térmico) foram obtidas pelo ESCm na maioria das zonas climáticas. A diferença de temperatura máxima entre ESCm e REFm foi em média de 0,3 ${ }^{\circ} \mathrm{C}$, atingindo $0,9^{\circ} \mathrm{C}$ na zona 5 no verão. A ESCm geralmente é seguida pela RBMFm, graças às propriedades térmicas dessas duas argamassas. Essa tendência foi mantida no verão e no inverno; no entanto, no verão, a inércia térmica para o resfriamento promovida pelo ESCm foi mais significativa. As argamassas REFm e QZTOm seguem com resultados muito semelhantes (diferença inferior a 5\% entre elas).

Esses resultados, apesar de promissores, indicam que uma diminuição na condutividade térmica das argamassas em até $50 \%$ e um aumento no armazenamento de calor sensível em até 33\% não foram tão eficazes na redução da temperatura geral quanto em algumas outras medidas. Por exemplo, Sá et al. (2012) encontraram diferenças na ordem de $2{ }^{\circ} \mathrm{C}$ nas temperaturas de pico ao adicionar $25 \%$ de materiais de mudança de fase (MMFs) às argamassas de revestimento. Franco et al. (2019) observaram diferenças de até $1{ }^{\circ} \mathrm{C}$ ao substituir completamente os agregados na vedação do edifício (blocos, concreto e argamassas) por escória de aciaria.

\section{CONCLUSÃO}

O presente estudo avalia o desempenho térmico de argamassas de revestimento produzidas com resíduos industriais e de mineração. Para isso, investigamos o efeito de quatro tipos de agregados (areia de rio, rejeitos de minério de ferro, quartzito friável e escória siderúrgica) sobre uma argamassa de revestimento. Procurando entender como as propriedades térmicas das argamassas influenciam o desempenho térmico de edifícios e suas implicações no conforto de seus usuários em diferentes climas, um edifício residencial foi simulado em oito zonas climáticas.

Entre as argamassas produzidas com resíduos, aquelas com escória de aciaria (ESCm) apresentaram os melhores resultados em todas as zonas climáticas brasileiras. Eles foram seguidos por argamassas com rejeitos de minério de ferro (RBMFm) com desempenho térmico semelhante. Este resultado está relacionado à baixa condutividade térmica e alta massa específica aparente desses materiais. As argamassas com rejeitos de quartzito (QZTOm) apresentaram valores de temperatura semelhantes ou ligeiramente piores que as argamassas convencionais (REFm), devido às suas propriedades físicas e térmicas semelhantes.

A diferença de temperatura de pico entre as argamassas com resíduos e a convencional alcançou $0,9^{\circ} \mathrm{C}$, sem alteração nos métodos de construção. Os resultados mostraram que as argamassas estudadas são alternativas viáveis para contribuir com a eficiência energética dos edifícios. Além disso, o uso dessas argamassas com redísuos é uma medida passiva de longa duração, não depende do comportamento do usuário e requer pouca manutenção, diminuindo os riscos de fissuras e infiltração, que são patologias comumente encontradas nas argamassas de revestimento. 
Nesse cenário, a incorporação de resíduos como agregados pode: diminuir o consumo de energia dos edifícios; reduzir a pegada de carbono do uso de agregados naturais; mitigar os impactos ambientais do depósito dos resíduos; diminuir os custos associados a essas melhorias; diminuir a demanda por manutenção. Portanto, o consumo de energia e os impactos ambientais da edificação são reduzidos tanto as fases de construção quanto na operacional. Além disso, um melhor desempenho térmico promovido pelos rejeitos pode aumentar a saúde, a produtividade e a felicidade dos usuários (PATINOA e SIEGEL, 2018). As consequências são não apenas sociais, mas também econômicas e ambientais, dado o uso mais racional dos recursos, com menor consumo de energia e reutilização de resíduos.

\section{AGREDECIMENTOS}

O presente trabalho foi realizado com apoio da Coordenação de Aperfeiçoamento de Pessoal de Nível Superior - Brasil (CAPES) - Código de Financiamento 001. Os autores também agradecem à FAPEMIG, CNPq e UFOP pelo apoio para a realização e apresentação dessa pesquisa. Somos gratos ainda pela infraestrutura e colaboração do Grupo de Pesquisa em Resíduos Sólidos - RECICLOS - CNPq.

\section{REFERÊNCIAS}

ABNT. NBR 13276 - Argamassa para Assentamento e Revestimento de Paredes e Tetos. Rio de Janeiro. 2002.

ABNT. NBR 10004 Resíduos Sólidos - Classificação. Rio de Janeiro. 2004.

ABNT. NBR 10007 -Amostragem de resíduos sólidos. Assosiação Brasileira de Norma Técnica. Rio de Janeiro. 2004.

ABNT. NBR 15220-Desempenho térmico em edificações. Associação Brasileira de Normas Técnicas. Rio de Janeiro. 2005 .

ABNT. NBR 9778-Argamassa e concreto endurecido - Determinação de absorção, vazios e massa específica. Associação Brasileira de Normas Técnicas. Rio de Janeiro. 2009.

ABNT. NBR 15575-Edifícios Residenciais - Desempenho. Associação Brasileira de Normas Técnicas. Rio de Janeiro. 2013.

BASTOS, L. et al. Using Iron Ore Tailings from Tailing Dams as Road Material. Journal of Materials in Civil Engineering, p. 04016102-1, 2016.

CARVALHO, J. M. et al. More eco-efficient concrete: An approach on optimization in the production and use of wastebased supplementary cementing materials. Construction and Building Materials, v. 206, p. 397-409, 2019.

COSTA, L. C. Desempenho de concretos de escória de aciaria frente a ataques de cloretos. Universidade Federal de Ouro Preto: Dissertação de Mestrado, 2019.

DA SILVA, et al. Feasibility Study of Steel Slag Aggregates in Precast Concrete Pavers. ACI Materials Journal , v. 113, p. 439-446, 2016.

DIAS , et al. Quartz mining residue for production of tile mortars. CBECiMat, Natal , 2017.

EDRAKI, M. et al. Designing mine tailings for better environmental, social and economic outcomes: a rewiew of alternative approaches. Journal of Cleaner Production, v. 84, p. 411-420, Dezembro 2014.

FONTES, ; MENDES, ; PEIXOTO, R. A. Mortars for laying and coating produced with iron ore tailings from tailing dams. Construction and Building Materials, v. 112, p. 988-995, 2016.

FRANCO, et al. Design and thermal evaluation of a social housing model conceived with bioclimatic principles and recycled aggregates. Sustainable Cities and Society, v. vol. 51, p. 101725, 2019.

MENDES, J. C. et al. On the relationship between morphology and thermal conductivity of cement-based composites. Cement and Concrete Composites, Outubro 2019. 
PATINOA, E. D. L.; SIEGEL, J. A. Indoor environmental quality in social housing: A literature review. Building and Environment, v. 131, p. 231-241, 2018.

SÁ, A. V. et al. Thermal enhancement of plastering mortars with phase change materials: experimental and numerical approach. Energy and Buildings, v. 49, p. 16-27, 2012.

SADINENI, S.; MADALA, ; BOEHM,. Passive building energy savings: A review of building envelope components. Renewable and Sustainable Energy Reviews, v. 15, p. 3617-3631, 2011.

SANT'ANA FILHO, J. N. et al. Technical and Environmental Feasibility of Interlocking Concrete Pavers with Iron Ore Tailings from Tailings Dams. ournal of Materials in Civil Engineering, v. 29, p. 04017104, 2017.

SANTOS ,. Total substitution of the natural aggregate by friable quartzite for the production of mixed mortars for laying and coating. Universidade Federal de Ouro Preto : Dissertação de Mestrado, 2015.

SANTOS , D. Ecomassa - Argamassas Mistas Produzidas com Estétil de Mineração. Universidade Federal de Ouro Preto. Ouro Preto. 2015.

SILVA, et al. Feasibility Study of Steel Slag Aggregates in Precast Concrete Pavers. ACI MATERIALS JOURNAL, v. 113, p. 439-446, 2016.

SONG, M. et al. Review on building energy performance improvement using phase change materials. Energy and Buildings, v. 158, p. 776-793, 2018. 